\title{
Temperature Control System Based on SCM
}

\author{
Yuxin Lei \\ No.280 Jinhua Road, Xincheng Disreict, Xi'an City, Shaanxi Province, China
}

\begin{abstract}
In order to control the indoor temperature in a given range automatically, use SCM(single chip microcomputer) 89C52 as the main part is a simple way. The design of the hardware part is shown as FIGURE I and the software part is compiled by 'Keil'. After simulating the system in 'Protues' then begin the experiment. This system can measure the real time temperature by $\mathrm{DS18B20}$ and compare it with the setting temperature, then control the situation of relays and display the results on the LCD1602.
\end{abstract}

Keywords-control; temperature;SCM; simulation; program

\section{INTRODUCTION}

Temperature is one of the most general and basic physical quantity, to measure and control this physical quantity is used in many different kinds of occasions, such as agricultural planting, industrial producing and daily life. Hence, temperature control is a significant factor which needs to be considered in these situations.

The main control part for this system is the SCM AT89C52 which is produced by the company ATMEL, and AT89C52 is a high performance and low cost component[6]. The temperature sensor DS18B20 is produced by a United States company -- Dallas. The function of DS18B20 in this system is to collect and convert the real time temperature signal[4]. In this project, temperature sensor DS18B20 collect and convert the real time temperature, and the result can be displayed on the LCD1602. Setting any range of temperature as you want and if the real time temperature is higher than the maximum of range, the cooling device will start to work, otherwise, the heating device will begin to work.

For the practical usage in life, the cooling device can be a refrigerator or an air-conditioner and the heating device can be a radiator or microwave oven. In the laboratory experiment, the safe and economy need to be considered, therefore, using a small DC fan and a cartridge heater to replace other cooling and heating devices.

\section{HARDWARE PART}

\section{A. Overview Function}

Using DS18B20 to collect and convert the real time temperature signal, and then setting the range of temperature through the push up buttons. When the real time temperature is higher than the maximum temperature, the relay 1 will operate and the fan will begin to work; and when the real time temperature is lower than the minimum temperature, the relay 2 will operate and the cartridge heater will begin to work. The solution of measurement and setting are all displayed on the
LCD1602 and it makes is clear to compare the real time temperature with the setting value.

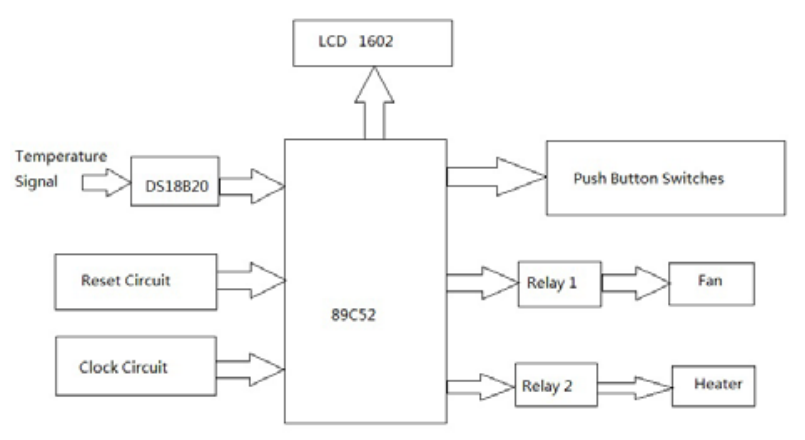

FIGURE I. BLOCK DIAGRAM OF TEMPERATURE CONTROL SYSTEM

\section{B. Oscillator/Clock Circit}

For the oscillator/clock, there has internal clock mode and external clock mode; the internal clock mode is chosen in this project. An internal clock mode circuit includes two capacitors and one crystal; connect the clock circuit with port XTAL1 and XTAL2 of the chip[5]. The clock signal leads every part of device to work synchronously, the greater value of frequency means the faster working speed of chip. The frequency range of crystal oscillator is from $1.2 \mathrm{MHz}$ to $12 \mathrm{MHz}$, the frequently-used are $6 \mathrm{MHz}$ and $12 \mathrm{MHz}$.

For a $12 \mathrm{MHz}$ crystal, the system cycle is $\frac{1}{12} \mu \mathrm{s}$, the oscillator or clock cycle (the period of completing microcomputer operation) is $\frac{1}{6} \mu$ s and the machine/instruction cycle (the period of completing basic operation) is $1 \mu \mathrm{s}$.

The value of load capacitor for a $12 \mathrm{MHz}$ crystal is $20 \mathrm{pF}$, if the value is too large, the precision of crystal will reduce; if the value is too small, the anti-interference of crystal will reduce. In consideration of errors and loss, we choose the value of capacitor is about $30 \mathrm{pF}$. The capacitors should be placed near the chip in order to reduce the error.

\section{Reset Circuit}

Reset circuit is formed by an electrolytic capacitor, a push up button and a resister.

Connect the $10 \mu \mathrm{F}$ electrolytic capacitor to the RST port of chip and the other end is 5V DC supply, parallel a push up button to the electrolytic capacitor, connect a $10 \mathrm{~K} \Omega$ resistor to port RST and the other end of resistor is connected to ground.

When the output of RST/VPD pin of 89C52 maintains high 
level equals or greater than 2 machine cycle, the chip will reset. For a $12 \mathrm{MHz}$, the machine cycle is $1 \mu \mathrm{s}$, therefore the high level of RST/VPD must maintain at least $2 \mu \mathrm{s}$ in order to reset.

\section{Temperature Collection Circuit}

The temperature measuring method of DS18B20 is to use an on chip measurement technology and the temperature range that can be measured by DS18B20 is from $-55^{\circ} \mathrm{C}$ to $125^{\circ} \mathrm{C}$. The temperature signal is converted to the quantity of nine digital and the typical time of conversion is about $200 \mathrm{~ms}$.

The procedure of temperature convention can be divided into three main parts. First of all, while the host machine working in reset operation, the response pulse of temperature sensor DS18B20 is also received by the host machine. Then, the command of skip ROM, which is a kind of operation command, is sent by the host machine. The advantage of skip $\mathrm{ROM}$ is it makes the operation simpler and can reduce the operation time. But we can only skip the ROM when there is only one device on the bus, if there are more than one devices on the bus, all the devices will response at same time when skip ROM, it will lead to data conflict. Finally, another operation command which is used to control conversion temperature is written by the host machine.

\section{E. Cooling and Heating Circuit}

These two circuits are almost same, the main components of circuit are: $5 \mathrm{~V}$ DC relay, NPN transistor, $2 \mathrm{~K} \Omega$ resistor, diode $1 \mathrm{~N} 4007$ and the cooling or heating device.

One end of $2 \mathrm{~K} \Omega$ resistor connects to the $\mathrm{I} / \mathrm{O}$ port of chip and other end connects to the BASE of transistor. The COLLECTOR connects to the coil of relay and the EMITTER connects to ground. Parallel a diode to the coil, the negative pole of diode connects to $5 \mathrm{~V}$ DC supply. The normally open contact connects to the cooling or heating device; the voltage supply connects to the other end of cooling and heating device.

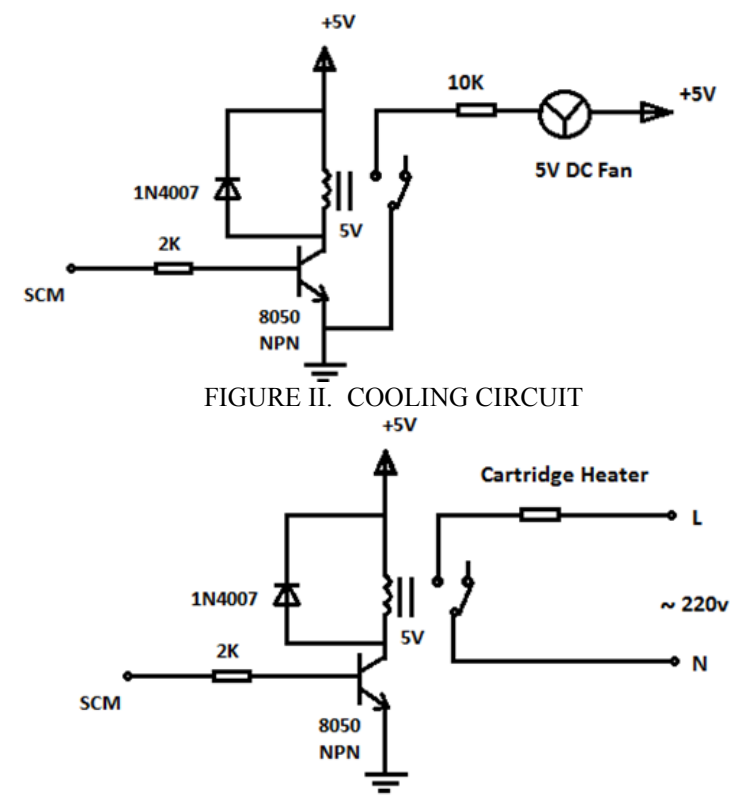

FIGURE III. HEATING CIRCUIT
For DC operation, the maximum value of operation voltage is $80 \%$ of rated voltage and for AC operation; the maximum value is $85 \%$ of its rated voltage.

If operation voltage is too small, the switch of relay cannot move; if the operation voltage is too large, the coil in relay may be burned out.

\section{F. Display Circuit}

The LCD1602 can be connected to MCU (Micro Control Unit) directly; therefore the LCD1602 is used widely by many electronic equipment and occasions.

Connect ports DB0 to DB7 (8 ports) to the ports P0.0 to P0.7 of the chip and also connect a resistor network as the pull-up resistor (the VCC port of resistor network need to be connected to $5 \mathrm{~V} \mathrm{DC}$ ). Port VSS is connected to ground, VDD is $5 \mathrm{~V}$ DC. Connect a $10 \mathrm{~K} \Omega$ potentiometer to port VEE, make VEE become an adjusting port, the other two ends of potentiometer connect to ground and 5V DC power supply. Port RS, R/W and E connect to P2.0, P2.1 and P2.2 of chip. The ports A and K of LCD1602 are the voltage supply of the back light of LCD, so connect port $\mathrm{A}$ to $5 \mathrm{~V} \mathrm{DC}$ and $\mathrm{K}$ to ground.[2]

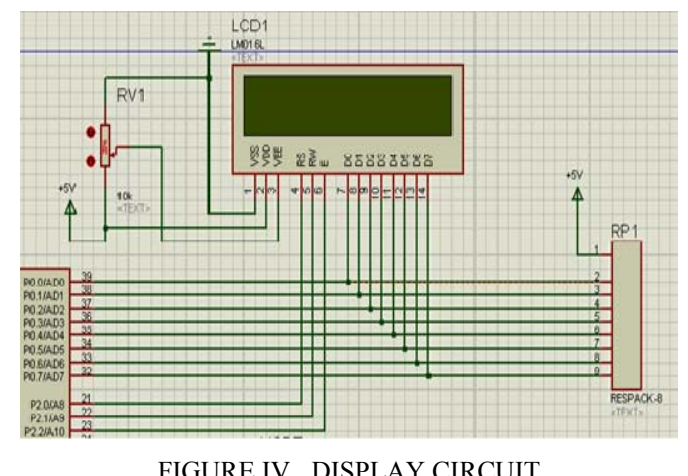

\section{SOFTWARE PART}

The design of software part in this project is based on $\mathrm{C}$ language programming. It is mainly used to control the temperature collection of DS18B20, the display of LCD1602 and the operation of relays.

\section{A. Software Keil}

Keil software is chosen to do the computer programming in this project. Keil C51 is produced by an American company named Keil Software which is one of the ARM companies. Keil software is world-leading software of Embedded Systems, the main functions of Keil are: compiling ANSI C, real time core, assembling macro, debugging and linking. And also Keil can be used to manage the library, simulate and develop some kinds of boards such as 251 and 8051. Compare with the assembler language, $\mathrm{C}$ language has obvious superiority in many aspects, for example, the functionality, readability, maintainability and constitutive property.

\section{B. Flow Chart}

For the beginning of program, the first step is to initialize 
the LCD and timer[5]. Then, command the DS18B20 to collect the temperature and display the value of real temperature on the LCD1602. Next, judge whether the temperature exceed the range which were set or not. After that, judge whether the push up button is pressed or not. If the button is pressed, then do the key processing and return to temperature collection. If the button is not pressed, return to temperature collection directly.

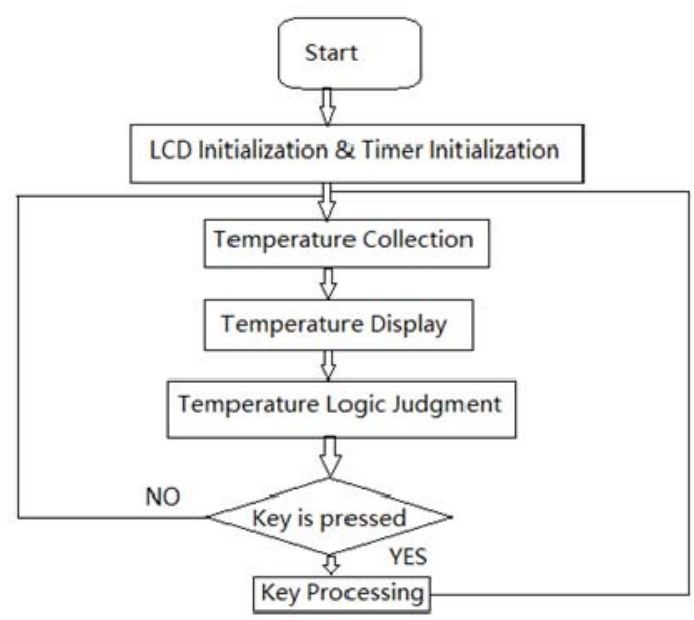

FIGURE V. FLOW CHART

\section{PROCEDURE}

\section{A. Simulation Part}

For the simulation part of this project, we use software Proteus 7 Professional. Software Proteus is EDA tool software which is published by a United Kingdom company--Lab Center Electronics. It can not only simulate the functions of other EDA tool software but can also simulate the peripheral devices of SCM (single chip microcomputer).It is a superior software to simulate SCM and the peripheral devices for the moment.

Before doing the simulation, the first step is to draw the circuit in software. First of all, find AT89C52 (the main chip), LM016L (16X2 Alphanumeric LCD), DS18B20, RESPACK8(resistor network), NPN (general transistor), POT-HG (variable potentiometer), CAP-ELEC, CAP, DIODE, CRYSTAL, BUTTON, RES, LED-RED and LED-GREEN (replace the Cartridge Heater and the Fan in simulation) in the 'Library'; then connect each components according to the schematic diagram; set the value of components and supplies. After finishing the circuit, download the hex file to the chip. Finally, debug the circuit, measure the typical points of circuit by the 'DC Voltmeter' and the 'DC Ammeter' and record the data.

\section{B. Practice Part}

According to the circuit we designed, place and weld the heating circuit on the print circuit board (because the rated current of cartridge heater is about $1 \mathrm{~A}$, the bread board cannot work well under this level of current) and place other components on the bread board. Weld the socket and the LCD by electric welding. Distinguish every pin and understand its function based on the data sheet of each component, and then connect them with wires. After connecting the components, we need to connect the laboratory DC voltage supply with the bread board and place the earth lines, set the output value of supply as 5V DC. Connect the cartridge heater with the box and put the plug into the jack. A reasonable overall arrangement can make it easy to check and correct the mistakes of the circuit. I use yellow wires to represent $5 \mathrm{~V} \mathrm{DC}$ and all the earth lines are black. We use software Keil to do the $\mathrm{C}$ programming and commissioning, after that we need to work out the Hex file from $\mathrm{C}$ file. Download the program download software and download the drive software of PL2302.Finally, record the $\mathrm{C}$ program into the single chip microcomputer by using USB to TTL PL2302 and then test it.

Switch on the generator, and set it as DC voltage mode, then set the value as 5V DC. Use the multi-meter to measure the value of voltages of mainly points.

\section{DATA RCORD}

\section{A. Simulation Part}

The data are measured by 'DC Voltmeter' in this simulation, the output value of DS18B20 and the value of RST port are measured.

TABLE I. VOLTAGES OF DS18B20 IN SIMULATION

\begin{tabular}{|l|l|}
\hline Points & Voltage/V \\
\hline Port DQ of DS18B20 & $5 \mathrm{~V}$ \\
\hline \multirow{2}{*}{ Port RST } & 5 Vwhen press the reset button) \\
\cline { 2 - 2 } & 2.86 Vnot press the reset button) \\
\hline
\end{tabular}

In this project, there are three different results: only cooling circuit is working; only heating circuit is working; and two circuits are all not working. The data record here divides into these three parts of different situations.

TABLE II. ONLY COOLING CIRCUIT IS WORKING IN SIMULATION

\begin{tabular}{|l|l|l|}
\hline Points & $\begin{array}{l}\text { Voltage of } \\
\text { Cooling Circuit/V }\end{array}$ & $\begin{array}{l}\text { Voltage of } \\
\text { Heating Circuit/V }\end{array}$ \\
\hline Input of resistor & $4.95 \mathrm{~V}$ & $0.02 \mathrm{~V}$ \\
\hline Input of transistor & $0.86 \mathrm{~V}$ & $0.02 \mathrm{~V}$ \\
\hline Coil of relay & $4.93 \mathrm{~V}$ & $0.00 \mathrm{~V}$ \\
\hline
\end{tabular}

TABLE III. COOLING CIRCUIT AND HEATING CIRCUIT ARE ALL NOT WORKING

\begin{tabular}{|l|l|l|}
\hline Points & $\begin{array}{l}\text { Voltage of } \\
\text { Cooling Circuit/V }\end{array}$ & $\begin{array}{l}\text { Voltage of } \\
\text { Heating Circuit/V }\end{array}$ \\
\hline Input of resistor & $0.02 \mathrm{~V}$ & $0.02 \mathrm{~V}$ \\
\hline Input of transistor & $0.02 \mathrm{~V}$ & $0.02 \mathrm{~V}$ \\
\hline Coil of relay & $0.00 \mathrm{~V}$ & $0.00 \mathrm{~V}$ \\
\hline
\end{tabular}


TABLE IV. ONLY HEATING CIRCUIT IS WORKING IN SIMULATION

\begin{tabular}{|l|l|l|}
\hline Points & $\begin{array}{l}\text { Voltage of } \\
\text { Cooling Circuit/V }\end{array}$ & $\begin{array}{l}\text { Voltage of } \\
\text { Heating Circuit/V }\end{array}$ \\
\hline Input of resistor & $0.02 \mathrm{~V}$ & $4.95 \mathrm{~V}$ \\
\hline Input of transistor & $0.02 \mathrm{~V}$ & $0.86 \mathrm{~V}$ \\
\hline Coil of relay & $0.00 \mathrm{~V}$ & $4.93 \mathrm{~V}$ \\
\hline
\end{tabular}

\section{B. Practice Part}

Measure the main points of circuit by using the multimeter. The output value of DS18B20 is $4.08 \mathrm{~V}$, it is different to the simulation value because there is a pull-up resistor in the port DQ of DS18B20 and part of voltage is taken by it. Measure the voltage of crystal can help to judge whether the crystal is working or not.

\section{TABLE V. VOLTAGES OF SYSTEM IN PRACTICE}

\begin{tabular}{|l|l|}
\hline Point & Voltage/V \\
\hline Port DQ of DS18B20 & $4.08 \mathrm{~V}$ \\
\hline Crystal & $1.74 \mathrm{~V}$ \\
\hline
\end{tabular}

\section{Error Analysis}

In simulation, all the devices and components are ideal but in real objection, there exist some loss in many forms, for example the thermal energy. The errors are regular and we should take the real objection value as standard.

Absolute error:

$$
\Delta \mathrm{x}=\mathrm{x}-\mathrm{A}
$$

Relative error:

$$
\gamma=\frac{\Delta x}{x} \times 100 \%
$$

TABLE VI. ERROR ANALYSIS OF TEMPERATURE

\begin{tabular}{|l|l|l|l|}
\hline $\begin{array}{l}\text { Measured } \\
\text { Temperature(x) } /{ }^{\circ} \mathrm{C}\end{array}$ & $\begin{array}{l}\text { Actual } \\
\text { Temperature(A) } /{ }^{\circ} \mathrm{C}\end{array}$ & $\begin{array}{l}\text { Absolute } \\
\text { Error } /{ }^{\circ} \mathrm{C}\end{array}$ & $\begin{array}{l}\text { Relative } \\
\text { Error/\% }\end{array}$ \\
\hline 21.5 & 21.1 & 0.3 & 1.40 \\
\hline 26.5 & 26.1 & 0.4 & 1.51 \\
\hline 25.8 & 26.1 & -0.3 & -1.16 \\
\hline 24.2 & 24.4 & -0.2 & -0.83 \\
\hline 22.7 & 22.6 & 0.1 & 0.44 \\
\hline
\end{tabular}

The error is because there are distance between DS18B20 and digital thermometer, and the accuracy of DS18B20 and thermometer are also different.

\section{ACKNOWLEDGMENT}

I would like take a chance to thanks my tutor Dr. Nikola Chalashkanov at the University of Leicester in England. Thanks for teaching me and correcting my ideas and my paper.
Also, thanks to all the tutors in the laboratory. They work to help us with all the practice problems and protect us from the accident. Finally, I am grateful of my classmates in the university. I would not do well without your generous help.

\section{REFERENCES}

[1] Xiaocui H. (2015) Infrared Remote Control Design Based on Single Chip Microcomputer, IEEE Computer Society.

[2] Shasha C., Sheng F. (2011) The Design of the Noise Detector Based on AT89C52 Microcontroller, IEEE Computer Society.

[3] Ted V. (2001) Programming Microcontrollers in C(Second Edition), Elservier Inc.

[4] Maxim Integrated Corporation Data Sheet (2008) Maxim Integrated Corporation Data Sheet for DS18B20 Programmable Resolution 1-Wire Digital Thermometer. <http://docseurope.electrocomponents.com/webdocs/078b/0900766b807 8b130.pdf>, accessed Aug 23, 2016.

[5] Yongxian S., Yuan F. (2011) Design of LED Display Control System Based on AT89C52 Single Chip Microcomputer, JOURNAL OF COMPUTERS, VOL. 6, NO. 4, APRIL 2011.

[6] Atmel Corporation Data Sheet (2006) Atmel Corporation Data Sheet for AT89C52.

<http://html.alldatasheet.com/htmlpdf/56216/ATMEL/AT89C52/126/1/A T89C52.html>, accessed Aug 23, 2016.

[7] Fairchild Semiconductor Corporation Data Sheet (2004) Faiechild semiconductor Corporation Data Sheet for SS8050 NPN Epitaxial transistor. 